\title{
Socioeconomic status and trends in risk factors for cardiovascular diseases in the Danish MONICA population, 1982-1992
}

\begin{abstract}
Merete Osler, Lars Ulrik Gerdes, Michael Davidsen, Henrik Brønnum-Hansen, Mette Madsen, Torben Jørgensen, Marianne Schroll
\end{abstract}

\begin{abstract}
Study objective-The decline in cardiovascular mortality in Denmark during the 1980s has been greatest in the highest socioeconomic groups of the population. This study examines whether the increased social inequality in cardiovascular mortality has been accompanied by a different trend in cardiovascular risk factors in different educational groups. Design-Data from three cross sectional WHO MONICA surveys conducted in 1982-84, 1987, and 1991-92, were analysed to estimate trends in biological (weight, height, body mass index, blood pressure, and serum lipids) and behavioural (smoking, physical activity during leisure, and eating habits) risk factors in relation to educational status.
\end{abstract}

Setting-County of Copenhagen, Denmark.

Participants-6695 Danish men and women of ages 30, 40, 50, and 60 years.

Main results-The prevalence of smoking and heavy smoking decreased during the study but only in the most educated groups. In fact, the prevalence of heavy smoking increased in the least educated women. There was no significant interaction for the remaining biological and behavioural risk factors between time of examination and educational level, indicating that the trend was the same in the different educational groups. However, a summary index based on seven cardiovascular risk factors improved, and this development was only seen in the most educated men and women.

Conclusion-The difference between educational groups in prevalence of smoking increased during the 1980s, and this accounted for widening of an existing social difference in the total cardiovascular risk.

(F Epidemiol Community Health 2000;54:108-113)

The incidence and mortality of cardiovascular diseases have decreased in Denmark during the past 15 years, as in most other Western countries. ${ }^{12}$ Similar to observations in Sweden, ${ }^{3}$ Finland, ${ }^{4}$ United Kingdom, ${ }^{5}$ and USA, ${ }^{6}$ the decline in cardiovascular mortality in Denmark during the 1980s has been most pronounced in the highest socioeconomic groups, widening the existing social inequality. ${ }^{7}$ Furthermore, a recent review of the relation between socioeconomic status and cardiovascular diseases in cohort and case-control studies published from 1960-1993 has shown that the magnitude of the tendency to lower social groups to have higher cardiovascular mortality has been strengthened in recent years. ${ }^{8} \mathrm{Al}-$ though several cohort studies have shown that more than half of the excess risk of cardiovascular events in lower socioeconomic status groups could be explained by biological and behavioural risk factors such as serum cholesterol, blood pressure, body mass index (BMI), smoking, and physical activity, few studies have analysed whether the increased socioeconomic difference in cardiovascular mortality during the 1980s has been accompanied by a growing social difference in the prevalence of cardiovascular risk factors. ${ }^{9-11}$

Education is one of the various indices of socioeconomic status, most strongly associated with cardiovascular mortality and morbidity, ${ }^{12}$ and the health differences according to level of education have among other things been attributed to the direct effects of education, including the acquisition of knowledge regarding health damaging behaviour. The preventive efforts aimed at reducing cardiovascular morbidity in Denmark have mainly rested on increasing the population's knowledge of risk factors through media-based health information on smoking, physical activity, and diet. On this background we hypothesised that the increased social inequality in cardiovascular mortality in Denmark would be associated mainly with different trends in behavioural cardiovascular risk factors in different educational groups. Thus, this study examines trends in cardiovascular risk factors in relation to level of education in middle aged men and women in Copenhagen County.

\section{Methods}

\section{PARTICIPANTS}

The design of the Danish WHO MONICA surveys has been described in detail previously. ${ }^{13}$ Briefly, random equal sized samples of 30, 40, 50 , and 60 year old men and women living in the south western part of Copenhagen County were drawn from the National Central Person Registry and invited to participate in surveys conducted in 1982-84 (DAN-MONICA I), 1987 (DAN MONICA II), and 1991-92 (DANMONICA III). The response rates were $79 \%$, $75 \%$, and $73 \%$, respectively, and after exclusion of immigrants, mainly persons from Turkey, former Yugoslavia and Pakistan (less than 5\%), 
data for 3317 women $(1822+737+778)$ and 3378 men $(1876+725+777)$ were available. Immigrants were excluded because they may tend to cluster on both biological variables and behavioural traits.

\section{DATA COLLECTION}

Data on well established biological and behavioural cardiovascular risk factors were collected by clinical examination and questionnaire, respectively. Comparable survey methods, which followed the WHO-MONICA protocol were used in all three surveys, and they have been described in earlier reports. ${ }^{13}$ Data on the biological variables, smoking, drinking and physical activity were missing from less than $1 \%$ of the participants, whereas $9.5 \%$ of the participants had not completed the questionnaire on dietary habits.

\section{CARDIOVASCULAR RISK FACTORS}

All anthropometric and blood pressure measures were collected by the same trained nurse in all studies. BMI was calculated as weight in kilograms divided by the square of height in metres. Blood pressure was measured with a London School of Hygiene sphygmomanometer, using one of three cuffs of different sizes. Measurements were done twice on the left arm with the participants having rested at least five minutes in supine position. All measurements in the three surveys were done by the same trained nurse who was subject to control of hearing. Preliminary data analyses showed that mean systolic blood pressure apparently decreased from 1982-84 to 1986-87, and then rose again in 1991-92. This peculiarity led to identification of a subtle difference in the examination programmes schedules (duration of rest before blood pressure measurements) as a likely source of variation, and data were re-analysed with exclusion of blood pressure data from the second survey. However, this did not change the results significantly. Blood samples for serum lipid analyses were taken after an overnight fast. Total cholesterol, and HDL-cholesterol were measured using the CHOD-PAP enzymatic method (Monotest $\mathrm{R}$ Cholestrol, Boehringer Mannheimer, Germany). The biochemical analyses were subject to internal laboratory quality control following the recommended protocols for the WHO MONICA project, and took full part throughout the three survey periods in the external quality assessment programme offered collaborating WHO MONICA centres by the WHO Regional Lipid Reference Centre in Prague. Results from this programme revealed consistent biases in the measurements of total cholesterol in the laboratory, amounting to an average of $+5.8 \%$ in $1982-84$, to $+3.4 \%$ in

Table 1 Calculation of the cardiovascular risk index

\begin{tabular}{llll}
\hline Variable & O Points & 1 Point & 2 Points \\
\hline Body mass index $\left(\mathrm{kg} / \mathrm{m}^{2}\right)$ & $<27$ & $27-30$ & $>30$ \\
Systolic blood pressure/diastolic blood pressure & $<140$ and $<95$ & $140-160$ & $>160$ or $\geqslant 95$ \\
Total cholesterol $(\mathrm{mmol} / \mathrm{l})$ & $<5.0$ & $5.0-6.5$ & $>6.5$ \\
HDL cholesterol $(\mathrm{mmol} / \mathrm{l})$ & $>1.2$ & $0.9-1.2$ & $<0.9$ \\
Smoking & No & $<15 \mathrm{~g} /$ day & $\geqslant 15 \mathrm{~g} /$ day \\
Leisure time physical activity & Group C or D & Group B & Group A \\
Healthy eating index & $<2$ & 2 & $>2$ \\
\hline
\end{tabular}

$1986-7$, and to $+1.1 \%$ in $1991-2$. The corresponding figures for HDL cholesterol measurements were $+3.9 \%,+3,0 \%$ and $2.7 \%$. All data used in this paper were adjusted to comply with these biases. ${ }^{13}$

Questions on smoking concerned current and previous habits (yes, occasionally, no/never), and the kinds and average daily quantities of tobacco consumed (cigarettes, cheroots, cigars, pipe). In the analyses of the data, occasional smokers were considered as non-smokers. A daily consumption of more than 15 grams of tobacco was defined as heavy smoking. Tobacco consumption was calculated by equating a cigarette to $1 \mathrm{~g}$ of tobacco, a cheroot to $3 \mathrm{~g}$ tobacco, and a cigar to $5 \mathrm{~g}$ tobacco.

Dietary habits were assessed using a short food frequency questionnaire with 26 food items as previously described. ${ }^{14}$ The alternatives in the frequency scale were: never, once a month or less, twice a month, once a week, two to three times a week, once a day, two to three times a day, and four times or more daily. Based on indices of overall diet quality, ${ }^{15}$ and the current recommendations for a healthy diet, we calculated a crude index by giving one point for each of the following five characteristics of the diet: (1) not consuming butter, margarine or animal fats daily, (2) consuming either raw or boiled vegetables at least once daily, (3) consuming either wholemeal white bread or wholemeal rye bread at least once daily, and (4) consuming fruit at least once daily. As there were relatively few participants in the two extreme categories (that is, those with 0 or 4 points), they were combined with the neighbouring categories to give three categories: a low value of the index ( 0 or 1 point), an average value (2 points), and a high value ( 3 or 4 points). Such indices of overall diet quality have been related to the risk of all cause mortality diseases in several prospective population studies. ${ }^{15}$

Data on leisure time physical activity were based on answers to a question for which the participants had to mark one of four alternatives: A, mostly sedentary; B, walking, bicycling or otherwise active at corresponding level at least four hours per week; C, going jogging or demanding sports, or doing heavy activity during leisure for at least three hours per week; D, long distance running or competitive sports several times per week. We defined people in group $\mathrm{A}$ as being inactive.

We calculated a cardiovascular disease risk index with both biological and lifestyle related variables. It was comparable to an index used in the FINMONICA survey, ${ }^{16}$ and was based on seven different risk factors each contributing 0,1 , or 2 points as shown in table 1 . This risk score has been shown to be a good way to summarise the combined effects of different risk factors on future cardiovascular risk, ${ }^{16}$ and this was confirmed in a preliminary survival analysis in the present population, where the risk score significantly increased the risk of myocardial infarction $(n=72)$ by $31 \%$ per unit increase after controlling for age and sex. 
Table 2 Number of participants in relation to education in men and women

\begin{tabular}{|c|c|c|c|c|c|c|c|c|}
\hline \multirow[b]{2}{*}{ Education } & \multicolumn{4}{|l|}{ Men } & \multicolumn{4}{|l|}{ Women } \\
\hline & $\begin{array}{l}1982-84 \\
\text { No (\%) }\end{array}$ & $\begin{array}{l}1986-87 \\
\text { No (\%) }\end{array}$ & $\begin{array}{l}1991-92 \\
\text { No (\%) }\end{array}$ & Total & $\begin{array}{l}1982-84 \\
\text { No (\%) }\end{array}$ & $\begin{array}{l}1986-87 \\
\text { No (\%) }\end{array}$ & $\begin{array}{l}1991-92 \\
\text { No (\%) }\end{array}$ & Total \\
\hline$\leqslant 7$ years & 655 (35) & $208(29)$ & $164(21)$ & 1027 & $651(36)$ & $190(26)$ & $171(27)$ & 1012 \\
\hline $8-9$ years & $525(28)$ & $224(31)$ & 241 (31) & 990 & $488(27)$ & $232(32)$ & $221(29)$ & 941 \\
\hline $10-11$ years & $491(26)$ & $204(28)$ & $254(33)$ & 950 & $511(28)$ & $240(33)$ & 298 (39) & 1049 \\
\hline$\geqslant 12$ years & $202(11)$ & $80(11)$ & $112(15)$ & 394 & $148(8)$ & $71(10)$ & $83(11)$ & 302 \\
\hline Total & 1872 & 761 & 771 & & 1798 & 733 & 773 & 3314 \\
\hline
\end{tabular}

SOCIOECONOMIC STATUS

The commonest indicators of socioeconomic status in epidemiological studies are education, occupation, income, or indices of social class. ${ }^{12-17}$ Our hypothesis was that an educational difference in cardiovascular risk factors increased during the $1980 \mathrm{~s}$, and therefore this study used education as the main indicator of socioeconomic status. Educational attainment was assessed with questions about the highest grade or year of regular schooling and the highest degree earned.

\section{STATISTICAL METHODS}

All data analyses were performed separately for men and women. We used multivariate regression models to analyse the influence of education and time on risk factors. Linear regression models were used for continuous variables, and logistic regression models for categorial variables. All the continuous biological risk factors and the summary index were approximately normally distributed. Educational level were divided into four categories: $0-7,8-9,10-11$, and over 12 years. Time was measured in days calculated as the number of years between 1 November 1982 and examination of the participant.

Firstly, risk factor trends were analysed for each educational group, in univariate models with time as the independent variable of interest. Age was associated with education and most risk factors (data not shown), and consequently age was included in all models. Secondly, to test whether the time trend was the same in the different educational groups, data were analysed in multivariate models with age, education, time, and a time education interaction term as covariates. As the three surveys were not conducted in fully comparable seasonal periods, seasonal variations were considered as potential sources of bias. Hence, for variables with potential seasonal variation (weight, BMI, blood pressure and serum lipids) all analyses were repeated with data on a subsample of participants $(n=3852)$ examined in the six months represented in all three surveys (February to April and August to October). All the data reported are based on the total sample, and whenever the regression

Table 3 Biological cardiovascular risk factors in realtion to education in different years from men and women aged 30-60 years in Copenhagen County, Denmark. Age adjusted mean and (SD)

\begin{tabular}{|c|c|c|c|c|c|c|c|c|c|c|}
\hline & \multicolumn{5}{|l|}{ Men } & \multicolumn{5}{|l|}{ Women } \\
\hline & $1982-84$ & $1986-87$ & $1991-92$ & $p$ value & & $1982-84$ & $1986-87$ & $1991-92$ & $p$ value & \\
\hline \multicolumn{11}{|l|}{ Height (m) } \\
\hline$\leqslant 7$ years & $173.7(4.2)$ & $174.8(3.1)$ & $176.9(3.8)$ & $<0.01$ & & $162.3(3.5)$ & $162.5(3.5)$ & $162.4(3.0)$ & 0.02 & \\
\hline $8-9$ years & $176.2(3.6)$ & $177.2(4.1)$ & $176.8(4.0)$ & $<0.01$ & & $163.3(3.4)$ & $164.0(3.2)$ & $164.1(4.3)$ & 0.04 & \\
\hline $10-11$ years & $177.3(3.8)$ & $177.6(4.5)$ & $178.2(4.0)$ & 0.11 & & $164.3(3.5)$ & $164.6(3.7)$ & $164.9(3.4)$ & 0.16 & \\
\hline \multicolumn{10}{|l|}{ Weight $(\mathrm{kg})$} & \\
\hline$\leqslant 7$ years & $78.8(7.9)$ & $79.2(6.6)$ & $88.3(13.5)$ & $<0.01$ & $0.06 \dagger$ & $64.4(7.2)$ & $64.6(6.2)$ & $66.2(8.1)$ & 0.06 & \\
\hline $8-9$ years & $79.1(7.5)$ & $81.6(7.7)$ & $80.9(8.0)$ & 0.05 & 0.17 & $63.8(6.7)$ & $65.3(7.1)$ & $67.1(7.9)$ & $<0.01$ & \\
\hline $10-11$ years & $77.7(6.7)$ & $78.1(7.0)$ & $80.8(7.4)$ & $<0.01$ & $<0.01$ & $63.3(6.5)$ & $64.9(7.3)$ & $64.5(7.7)$ & 0.03 & \\
\hline $\begin{array}{l}\geqslant 12 \text { years } \\
B M I\left(\mathrm{~kg} / \mathrm{m}^{2}\right)\end{array}$ & \multicolumn{9}{|c|}{$B M I\left(\mathrm{~kg} / \mathrm{m}^{2}\right)$} & \\
\hline$\leqslant 7$ years & $26.1(2.2)$ & $25.9(2.1)$ & $28.1(3.7)$ & 0.02 & $0.69 \dagger$ & $24.5(2.5)$ & $24.5(2.2)$ & $25.1(2.9)$ & 0.14 & \\
\hline $8-9$ years & $25.5(2.2)$ & $26.0(2.1)$ & $25.9(2.3)$ & 0.17 & 0.41 & $23.9(2.4)$ & $24.3(2.6)$ & $24.9(3.0)$ & 0.01 & \\
\hline $10-11$ years & $24.7(1.8)$ & $24.8(1.9)$ & $25.4(2.0)$ & $<0.01$ & 0.05 & $23.4(2.3)$ & $24.0(2.5)$ & $23.7(2.5)$ & 0.18 & \\
\hline$\geqslant 12$ years & $24.5(1.7)$ & $24.8(1.9)$ & $24.7(1.8)$ & 0.26 & 0.36 & $23.2(1.9)$ & $23.0(1.8)$ & $23.0(2.1)$ & 0.16 & \\
\hline \multicolumn{11}{|c|}{ Diastolic $\mathrm{BP}(\mathrm{mm} \mathrm{Hg})$} \\
\hline$\leqslant 7$ years & $75.9(5.7)$ & $75.7(5.2)$ & $79.0(7.3)$ & 0.01 & & $70.3(5.3)$ & $72.0(5.5)$ & $72.1(5.1)$ & 0.04 & $0.78 \dagger$ \\
\hline $8-9$ years & $74.8(5.5)$ & $76.0(5.5)$ & $76.6(5.5)$ & 0.03 & & $70.4(5.7)$ & $71.1(5.6)$ & $72.8(5.7)$ & 0.02 & 0.01 \\
\hline $10-11$ years & $74.5(5.9)$ & $75.2(5.5)$ & $74.7(5.8)$ & 0.91 & & $70.3(5.4)$ & $71.7(5.8)$ & $72.2(5.7)$ & 0.27 & 0.23 \\
\hline$\geqslant 12$ years & $74.5(5.5)$ & $75.3(5.1)$ & $74.5(6.7)$ & 0.09 & & $70.6(5.2)$ & $70.0(4.9)$ & $72.0(5.7)$ & 0.97 & 0.48 \\
\hline \multicolumn{11}{|c|}{ Systolic $B P(m m ~ H g)$} \\
\hline$\leqslant 7$ years & $124.7(7.9)$ & $121.2(7.8)$ & $126.9(11.1)$ & 0.25 & & $117.8(7.8)$ & $115.1(8.4)$ & $117.9(8.1)$ & 0.87 & \\
\hline $8-9$ years & $124.9(7.6)$ & $121.5(7.2)$ & $124.4(8.0)$ & 0.82 & & $118.7(8.1)$ & $114.9(7.9)$ & $118.1(8.3)$ & 0.63 & \\
\hline $10-11$ years & $124.2(8.1)$ & $121.5(7.2)$ & $123.7(8.1)$ & 0.85 & & $119.0(7.9)$ & $115.2(7.9)$ & $117.6(8.2)$ & 0.32 & \\
\hline$\geqslant 12$ years & $122.0(8.3)$ & $120.7(9.2)$ & $122.2(9.8)$ & 0.56 & & $119.0(6.9)$ & $114.5(6.9)$ & $118.2(9.4)$ & 0.91 & \\
\hline \multicolumn{11}{|c|}{ Total cholesterol $(\mathrm{mmol} / \mathrm{l})$} \\
\hline$\leqslant 7$ years & $5.94(0.73)$ & $6.04(0.62)$ & $6.05(0.66)$ & 0.52 & & $5.89(0.60)$ & $6.01(0.62)$ & $5.66(0525)$ & 0.14 & \\
\hline $8-9$ years & $5.78(0.65)$ & $5.89(0.68)$ & $5.79(0.64)$ & 0.81 & & $5.85(0.58)$ & $5.73(0.58)$ & $5.66(0.61)$ & 0.07 & \\
\hline $10-11$ years & $5.86(0.69)$ & $5.91(0.61)$ & $5.64(0.75)$ & 0.07 & & $5.68(0.61)$ & $5.52(0.52)$ & $5.57(0.57)$ & 0.36 & \\
\hline$\geqslant 12$ years & $5.64(0.69)$ & $5.88(0.68)$ & $5.54(0.62)$ & 0.25 & & $5.42(0.56)$ & $5.66(0.61)$ & $5.33(0.51)$ & 0.29 & \\
\hline \multicolumn{11}{|c|}{ HDL-cholesterol (mmol/l) } \\
\hline$\leqslant 7$ years & $1.27(0.21)$ & $1.28(0.21)$ & $1.24(0.25)$ & 0.66 & & $1.57(0.24)$ & $1.55(0.21)$ & $1.44(0.22)$ & 0.07 & $<0.01 \dagger$ \\
\hline $8-9$ years & $1.32(0.24)$ & $1.27(0.20)$ & $1.27(0.22)$ & 0.03 & & $1.58(0.23)$ & $1.58(0.21)$ & $1.50(0.27)$ & 0.02 & 0.11 \\
\hline $10-11$ years & $1.32(0.34)$ & $1.36(0.19)$ & $1.21(0.19)$ & 0.04 & & $1.66(0.25)$ & $1.63(0.24)$ & $1.61(0.26)$ & 0.03 & 0.07 \\
\hline$\geqslant 12$ years & $1.29(0.20)$ & $1.36(0.22)$ & $1.24(0.18)$ & 0.06 & & $1.65(0.25)$ & $1.64(0.24)$ & $1.60(0.23)$ & 0.02 & 0.38 \\
\hline
\end{tabular}

${ }^{\star} \mathrm{p}$ values for the time term in linear regression models including age in total sample; $\mathrm{tp}$ values for comparable season subsamples differ. 
Table 4 Behavioural cardiovascular risk factors (age adjusted \%) and risk index valued (age adjusted mean and (SD)) in relation to education in different years from men and women aged 30-60 years in Copenhagen County, Denmark

\begin{tabular}{|c|c|c|c|c|c|c|c|c|c|c|}
\hline & \multicolumn{5}{|l|}{ Men } & \multicolumn{5}{|l|}{ Women } \\
\hline & $1982-84$ & $1986-87$ & 1991-92 & $p$ value ${ }^{*}$ & & $1982-84$ & $1986-87$ & 1991-92 & $p$ value $e^{\star}$ & \\
\hline \multicolumn{11}{|l|}{ Smokers } \\
\hline$\leqslant 7$ years & 67 & 59 & 66 & $<0.01$ & & 55 & 56 & 66 & 0.19 & \\
\hline $8-9$ years & 58 & 56 & 57 & 0.67 & & 51 & 47 & 52 & 0.80 & \\
\hline $10-11$ years & 53 & 45 & 45 & $<0.01$ & & 45 & 41 & 40 & 0.38 & \\
\hline$\geqslant 12$ years & 52 & 35 & 29 & $<0.01$ & & 44 & 25 & 25 & 0.01 & \\
\hline \multicolumn{11}{|c|}{ Heavy smokers } \\
\hline$\leqslant 7$ years & 50 & 58 & 53 & 0.48 & & 33 & 40 & 36 & 0.04 & \\
\hline $8-9$ years & 38 & 41 & 41 & 0.39 & & 28 & 31 & 30 & 0.28 & \\
\hline $10-11$ years & 36 & 34 & 31 & 0.08 & & 19 & 26 & 24 & 0.22 & \\
\hline$\geqslant 12$ years & 31 & 20 & 17 & $<0.01$ & & 16 & 14 & 8 & 0.02 & \\
\hline \multicolumn{11}{|c|}{ Inactive during leisure } \\
\hline$\leqslant 7$ years & 25 & 31 & 20 & 0.33 & & 38 & 41 & 47 & 0.90 & \\
\hline $8-9$ years & 20 & 25 & 21 & 0.67 & & 33 & 28 & 34 & 0.88 & \\
\hline $10-11$ years & 20 & 26 & 22 & 0.99 & & 28 & 30 & 26 & 0.61 & \\
\hline$\geqslant 12$ years & 30 & 30 & 28 & 0.74 & & 29 & 22 & 20 & 0.05 & \\
\hline \multicolumn{11}{|c|}{ Healthy eating } \\
\hline$\leqslant 7$ years & 10 & 16 & 25 & $<0.01$ & & 24 & 39 & 29 & 0.05 & \\
\hline $8-9$ years & 12 & 21 & 21 & $<0.01$ & & 24 & 31 & 30 & 0.07 & \\
\hline $10-11$ years & 17 & 16 & 17 & 0.74 & & 32 & 40 & 42 & $<0.01$ & \\
\hline$\geqslant 12$ years & 17 & 21 & 18 & 0.46 & & 31 & 44 & 45 & 0.03 & \\
\hline \multicolumn{11}{|c|}{ Total risk index $(0-14)$} \\
\hline$\leqslant 7$ years & $5.96(1.33)$ & $5.99(1.56)$ & $6.58(1.68)$ & 0.57 & $0.45 \dagger$ & $4.93(1.22)$ & $4.52(1.22)$ & $5.24(1.21)$ & 0.24 & $0.99 \dagger$ \\
\hline $8-9$ years & $5.44(1.29)$ & $5.35(1.38)$ & $5.50(1.40)$ & 0.09 & 0.65 & $4.74(1.16)$ & $4.46(1.29)$ & $4.83(1.30)$ & 0.05 & $0.75^{\circ}$ \\
\hline $10-11$ years & $5.06(1.27)$ & $5.01(1.40)$ & $5.13(1.42)$ & 0.78 & 0.61 & $4.17(1.07)$ & $4.07(1.24)$ & $3.92(1.11)$ & 0.94 & 0.28 \\
\hline$\geqslant 12$ years & $4.90(1.26)$ & $4.44(1.19)$ & $4.31(1.33)$ & 0.24 & 0.02 & $4.08(1.19)$ & $3.34(1.01)$ & $3.36(0.97)$ & $<0.01$ & 0.02 \\
\hline
\end{tabular}

${ }^{\star} \mathrm{p}$ values for the time time in logitistic regression models including age in total sample; $\nmid \mathrm{p}$ values for comparable season subsamples differ.

coefficient based on the season specific data differed by more than $15 \%$ from the coefficients based on all the data, we have reported the signifcance level from both analyses. Data analyses were performed using SPSS version 7.0.

\section{Results}

Men were better educated than women, and educational level increased over time in both sexes (table 2). The analyses of time trends from 1982 to 1992 in biological risk factors in each educational group showed that HDLcholesterol concentrations declined in women in all educational groups, and in the highest educated men. Increases in height, and diastolic blood pressure were significant in men and women with less than 10 years of schooling,

Table 5 V Values from multivariate analysis of interactions between time and educational status

\begin{tabular}{|c|c|c|c|}
\hline Variables & Education & Time & Time $^{\star}$ education \\
\hline \multicolumn{4}{|l|}{$\overline{M e n}$} \\
\hline Height & $<0.01$ & 0.01 & 0.51 \\
\hline Weight & 0.13 & $0.010 .19^{\star}$ & 0.66 \\
\hline BMI & $<0.01$ & $0.020 .88^{\star}$ & 0.84 \\
\hline Systolic blood pressure & 0.31 & 0.17 & 0.31 \\
\hline Diastolic blood pressure & 0.21 & 0.02 & 0.21 \\
\hline Total cholesterol & $0.02<0.01^{\star}$ & 0.43 & 0.11 \\
\hline HDL-cholesterol & $<0.01$ & 0.98 & $0.050 .11^{\star}$ \\
\hline Smoking & $<0.01$ & 0.77 & $<0.01$ \\
\hline Heavy smoking & 0.02 & 0.02 & $<0.01$ \\
\hline Inactivity during leisure & 0.99 & 0.79 & 0.83 \\
\hline Healthy eating & $<0.01$ & $<0.01$ & 0.02 \\
\hline Multiple risk index & $<0.01$ & 0.14 & $0.060 .37^{\star}$ \\
\hline \multicolumn{4}{|l|}{ Women } \\
\hline Height & $<0.01$ & 0.02 & 0.23 \\
\hline Weight & 0.22 & 0.02 & 0.68 \\
\hline BMI & $<0.01$ & 0.10 & 0.85 \\
\hline Systolic blood pressure & 0.07 & 0.78 & 0.74 \\
\hline Diastolic blood pressure & $<0.01$ & 0.11 & 0.54 \\
\hline Total cholesterol & $<0.01$ & 0.31 & 0.95 \\
\hline HDL-cholesterol & $<0.01$ & 0.03 & 0.29 \\
\hline Smoking & $<0.01$ & 0.01 & $<0.01$ \\
\hline Heavy smoking & $<0.01$ & $<0.01$ & 0.02 \\
\hline Inactivity during leisure & $<0.01$ & 0.47 & 0.25 \\
\hline Healthy eating & $<0.01$ & 0.55 & 0.39 \\
\hline Multiple risk index & $<0.01$ & $0.11<0.01^{\star}$ & 0.03 \\
\hline
\end{tabular}

${ }^{\star} \mathrm{p}$ values for comparable season subsamples differ. while an increase in weight and BMI was significant for men with 10-11 years of schooling and in women with 8-9 years. Systolic blood pressure, and total cholesterol, did not change significantly in any educational group (table 3).

Smoking and heavy smoking decreased most in the highest educated groups, and the proportion of heavy smokers in fact increased in the lowest educated women (table 4). The changes in the highest educated groups were attributable mostly to an increased prevalence of never smoking from the first to the second survey, whereas the changes from the second to the third survey were attributable to an increased prevalence of ex-smokers (data not shown). The proportion of physically inactive men did not change, but this frequency decreased in women with more than 11 years of schooling. The proportion with the most frequent intake of wholemeal bread, fruit, and vegetables increased in all educational groups in women, and in the least educated men. However, changes in the women were seen mostly from the first to the second survey. The summary index based on the seven cardiovascular risk factors improved with time, but this development was only significant in the highest educated men and women. This result did not retain significant when smoking was excluded from the index. In the regression models across educational groups, with the interaction between time and education testing the hypothesis that the trend was the same in the different educational groups, the interaction term was not significant in any of the models for each of the nine biological risk factors as the dependent variables (table 5). In the regression models across educational groups, test for interaction between time and education showed significance in models with smoking, heavy smoking, and the summary index. 


\section{Discussion}

This study showed that during the 1980s the difference between educational groups in the prevalence of smoking increased. There were no significant interactions between time of examination and educational level for the remaining biological and behavioural risk factors, indicating that the trend was the same in the different educational groups. A social gradient in a summary index based on seven risk factors also increased, but mainly because of smoking changes. This finding does not support our hypothesis that the increased social inequality in cardiovascular mortality in Denmark, would mainly be associated with a widening of a known educational difference in the behavioural cardiovascular risk factors. A few other studies from Finland, ${ }^{4}$ Australia, ${ }^{10}$ and USA ${ }^{18} 19$ have analysed trends in cardiovascular risk factors in relation to level of education during the 1980s. The two studies from USA found no educational difference in changes over time in smoking, blood pressure, cholesterol or BMI, while the studies from Finland and Australia observed increasing educational differences for smoking and BMI in women, though only for BMI in the Finnish men. There were no educational differences in trends for blood pressure, cholesterol or physical activity in these two studies. ${ }^{410}$ In a study from West Germany, social class gradients (assessed using a index comprising income, education and occupational status) increased between 1984 and 1991 for hypertension in men, smoking and overall cardiovascular risk in women. ${ }^{20}$

Why has the prevalence of smoking decreased mainly among persons with a high education enhancing an existing social difference? Educational differences in health behaviour have been attributed to the acquisition of knowledge regarding health damaging behaviour. However, even in studies in which educational differences in knowledge of the health consequences of smoking have been considered, strong associations between education and smoking are present, suggesting that effects beyond those of knowledge are involved. Education may serve as an indicator of life course socioeconomic position and promotor of important psychosocial attributes-in a smoking context-such as self efficacy, which has been associated with smoking cessation. However, in this study the decrease in smoking prevalence in the highest educated was mostly attributable to an increased prevalence of never smoking during the first study period. You could therefore argue that the changes in smoking behaviour have corresponded to a hierarchical diffusion model, non-smoking being first adopted among higher social classes, with the lower social classes following after a time lag usually of $5-10$ years. However, it is also possible that the higher educated have become more aware of their behaviour, and that the changes shown in studies reflect reported rather than actual changes in behaviour. On the other hand, in a study in which social differences in smoking were validated by measures of serum cotinin, there was no
KEY POINTS

- From 1982 to 1992 the prevalence of smoking decreased mainly in Danish adults with a high education increasing an existing social difference.

- For other biological (weight, height, body mass index, blood pressure, and serum lipids) and behavioural (physical activity during leisure, and eating habits) risk factors, the time trend was the same in the different educational groups.

- In Denmark the increased socioeconomic difference in cardiovascular mortality during the 1980s only seems to be accompanied by a growing social difference in the prevalence of smoking.

significant social difference in the misclassification of smokers and non-smokers. ${ }^{21}$

The prevalence of smoking was higher in men, but the decrease was most pronounced in men and at the end of the study period the least educated women showed the highest prevalence of smoking. This less favourable development in the least educated women has also been reported in other studies, ${ }^{22}$ and has led to more analytical studies in order to get a better understanding of less favourable development in the poorest educated women and to initiation of targeted interventions.

Our finding that level of biological risk factors for cardiovascular diseases remained largely constant during the study period is unexpected considering the evolution of treatments for hypertension and hyperlipidaemia, and although the access to the health services is free in Denmark, the social gradient did not improve for these variables.

It is important to consider some methodological issues when evaluating our results. The surveys were conducted following a standardised protocol with respect to sampling frames, measurement methods, and measures to minimise drifts in variable measurement levels that could be interpreted erroneously as time trends. ${ }^{13}$ The participation rate dropped from $79 \%$ in MONICA 1 to $73 \%$ in MONICA 3. A total of 1069 non-participants answered a short questionnaire by telephone and these data showed in all three surveys that, compared with participants, non-participants were more often women, older, less educated, and smokers. The prevalence of smoking decreased in the male non-participants in all age groups, while in the female non-participants changes were small and not significant. Very few non-participants had high education, and it was not possible to study trends in smoking behaviour in relation to educational status in the same way as reported for participants. However, the data suggested that there was also an increasing educational difference in the prevalence of smoking among male non-participants, and this suggests that our results could not be explained just by selective non-participation. The surveys were not conducted in fully comparable seasonal periods, and to bypass a combined influence of season on biological traits, 
and of confounding by unrecognised factors linked to participation schedule, we repeated the analysis in comparable subsets of the available data in the analyses. We preferred this approach to adjusting by mathematical modelling because preliminary analyses showed the effects of season to be inconsistent among the gender and age groups included in the surveys. Any long term comparison of the relation between level of education and cardiovascular risk factors is made difficult by the fact that the actual composition of educational groups has changed over the years. The lowest educated group has declined in size, in response to upward mobility of many of its members to better educated groups. As a result, those who have remained in the lowest education groups are probably at a greater relative disadvantage than were their predecessors. Notwithstanding this, it seems that the changes of educational level during this 10 year period have not been of a sufficient magnitude to explain all the increases in educational risk differences found in this study.

If smoking is a causal factor, then the relative change in incidence rate from period $a$ to period $b$ because of a change in prevalence of smokers from $\mathrm{p}_{\mathrm{a}}$ and $\mathrm{p}_{\mathrm{b}}$ can be approximated as $\left[\left(I_{a}-I_{b}\right) / I_{a}=\left(p_{b}-p_{a}\right) /\left[(R R-1)^{-1}+p_{a}\right]\right.$, where RR is the relative risk for smokers compared with non-smokers. For example, if smoking is associated with a constant relative risk around 2, and the prevalence of smokers decline in the highest educated men from $50 \%$ ot $25 \%$, the incidence rate of cardiovascular diseases would decline about $15 \%$, whereas the $10 \%$ decline in smoking prevalence among the least educated men would account for a $6 \%$ decrease in incidence rate. Thus, the changes in the prevalence of smoking in men in the DAN-MONICA population during 1982 through 1992 can explain some of the increase in social inequalities in cardiovascular disease rates. Therefore we conclude that, during the 1980s, the difference between educational groups in prevalence of smoking increased, and that this accounted for a widening of an existing social difference in the total cardiovascular risk.

Funding: this study received grants from the Danish Heart Foundation.

\section{Conflicts of interest: none.}

1 Osler M, Sørensen TIA, Sørensen S, et al. Trends in mortality and morbidity coronary heart disease in Denmortality and morbidity coronary heart disease in

2 Kirchhoff M, Davidsen M, Brønnum-Hansen H, et al. Incidence of myocardial infarction in the Danish MONICA dence of myocardial infarction in the Danish MONICA
population 1982-1991. Int f Epidemiol 1999;28:211-18.

population 1982-1991. Int f Epidemiol 1999;28:211-18.
3 Hallqvist J, Lundberg M, Diderichsen F, et al. SocioecoHallqvist J, Lundberg M, Diderichsen F, et al. Socioeco-
nomic differences in risk of myocardial infarction 19711994 in Sweden: time trends, relative risks and population attributable risks. Int f Epidemiol 1998;27:410-15.

4 Pekkanen J, Tuomilehto J, Uutela A, et al. Social class, health behaviour, and mortality among men and women in Eastern Finland. BMF 1995;311:589-93.

5 Mheen PJM, Smith GD, Hart C, et al. Socioeconomic differentials in mortality among men within Great Britain: time trends and contributory causes. 7 Epidemiol Community Health 1998;52:214-18.

6 Feldman JJ, Makuc DM, Kleinman JC, et al. National trends in educational differentials in mortality. Am $\mathcal{F}$ Epidemiol 1989;129:919-33.

7 Ingerslev O, Madsen M, Andersen O. Social difference in mortality in Denmark. Copenhagen: Ministry of Health,

8 Gonzalez MA, Artalejo FR, Calero JR. Relationship between socioeconomic status and ischaemic heart disease in cohort and case-control studies 1960-1993. Int F Epidemiol 1998;27:350-8.

9 Kaplan GA, Keil JE. Socioeconomic factors and cardiovascular disease: a review of the literature. Circulation 1993;88 1973-98.

10 Bennett S. Cardiovascular risk factors in Australia: trends in socioeconomic inequalities. F Epidemiol Community Health 1995;49:363-72.

11 Vartiainen E, Pekkanen J, Koskinen S, et al. Do changes in cardiovascular risk factors explain the increasing socioeconomic difference in mortality from ischaemic heart disease in Finland? f Epidemiol Community Health 1998;52:416-19.

12 Smith GD, Hart C, Hole D, et al. Education and occupational social class: which is the more important indicator of mortality risk? I Epidemiol Community Health 1998;52:153-60.

13 Gerdes LU, Brønnum-Hansen H, Madsen M, et al. Trends in selected biological risk factors for cardiovascular diseases in selected biological risk factors for cardiovascular diseases
in the Danish MONICA population 1982-1992. F Clin Epidemiol (in press)

14 Osler M, Heitmann BL. The validity of a short food frequency questionnaire and its ability to measure changes in food intake. Int F Epidemiol 1996;25:1023-30.

15 Kant AK. Indices of overall diet quality: a review. Am $\mathcal{F}$ Diet Assoc 1996;96:785-91.

16 Luoto R, Pekkanen J, Uutela A, et al. Cardiovascular risks and socioeconomic status: difference between men and women in Finland. F Epidemiol Community Health 1994;48: 348-54

17 Liberatos P, Link BG, Kelsey JL. The measurement of social class in epidemiology. Epidemiol Rev 1988;10:87-121.

18 Winkleby MA, Jatulis DE, Frank E, et al. Socioeconomic status and health: how education, income and occupation contribute to risk factors for cardiovascular disease. $A m \mathcal{F}$ Public Health 1992;82:816-20.

19 Reynes JF, Lasater TM, Feldman $\mathrm{H}$, et al. Education and risk factors for coronary heart disease: results from a New risk factors for coronary heart disease: results from a Nen

20 Helmert U, Shea S, Maschenwsky-Schneider U. Social class and cardiovascular disease risk factor changes in Wester germany 1984-1991. Eur f Public Health 1995;5:103-8.

21 Suadicani P, Hein HO, Gyntelberg F. Serum validated tobacco use and social inequalities in risk of ischaemic heart disease. Int f Epidemiol 1994;23:293-300.

22 Osler M, Prescott E, Gottscau A, et al. Trends in the prevalence in Danish adults, 1964-1994. The influence of gender, age, and education. Scand F Soc Med 1998;26:293- 